\title{
Partial Absence of the Right Ventricular Muscle in an Aged
}

\author{
Masaya Sugrura, M.D., Terumi Hayashi, M.D., \\ and Kunihiro Ueno, M.D.
}

\begin{abstract}
Summary
A case of partial absence of the right ventricular musculature was reported. The patient, 84-year-old female, had no cardiac symptoms or signs. The muscular defect of the right ventricle was first found at autopsy. It was $15 \times 12 \mathrm{~mm}$. in size, located at the pulmonary conus and was histologically composed of endocardial and pericardial layers.
\end{abstract}

\section{Additional Indexing Words :}

Muscular defect Uhl's anomaly Congenital heart disease

$7 \mathrm{HE}$ muscular defect of the right ventricle is a very rare cardiac malformation. Few reports have been presented since the first report by Uhl1)-12) and most of this anomaly died early in their lives. This is a report of such a case, who had no cardiac symptoms or signs during her life of 84 years, due probably to the least muscular defect ever reported.

\section{CASE RePort}

Y.S., an 84-year-old female, was admitted to the Yoiku-in Hospital on April 20, 1965 with chief complaints of anorexia, fever and urinary incontinence. She had been operated on for gastric ulcer at the age of 70 . Physical examination revealed a well nourished woman with marked kyphosis. Her pulse was regular with the rate of $84 / \mathrm{min}$, and her blood pressure was $128 / 84 \mathrm{~mm}$. Hg. Breath sounds were clear and the heart sounds were normal with no murmurs. The abdomen was flat and there were no palpable masses. Edema was not noted, and neurological examinations were negative, except urinary incontinence. Laboratory examinations showed almost normal values except slight anemia (hemoglobin content $59 \%$ and red blood cell count $396 \times 10^{4}$ ). The chest X-ray films demonstrated somewhat increase of the pulmonary vascular markings, and the cardio-thoracic ratio $(53 \%)$ was not increased (Fig. 1). Electrocardiograms showed the tendency of left axis deviation $\left( \pm 0^{\circ}\right)$, high voltage of $R$ waves in left precordial leads $\left(R_{\nabla_{5}}=3.6 \mathrm{mV}\right.$.)

From the Department of Internal Medicine, Yoiku-in Hospital, Tokyo Municipal Home for the Aged, Itabashi, Tokyo.

Received for publication April 22, 1970.

This case was presented at the 209th Kanto Regional Meeting of the Japanese Society of Internal Medicine on February 14, 1970. 


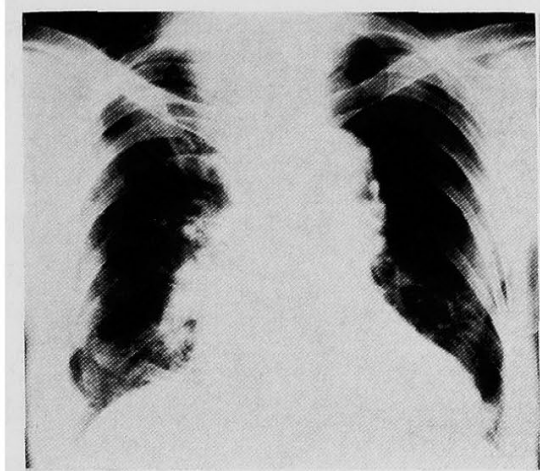

Fig. 1. X-ray film of the chest.

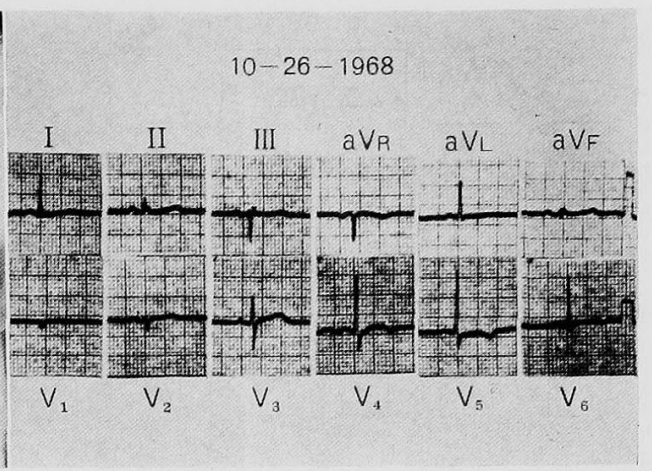

Fig. 2. Electrocardiogram.

and inverted $\mathrm{T}$ waves in leads $\mathrm{V}_{4-6}$ (Fig. 2). After admission, anorexia and fever disappeared and she had an uneventful course until September 25, 1969, when meteorism, vomiting and peristaltic rushes appeared, and she was diagnosed as mechanical ileus. Surgical therapy was done, but postoperative course was complicated by pneumonia and she died on October 15, 1969. Clinical diagnosis was spondylosis deformans, paralytic ileus and bronchopneumonia.

Autopsy showed brown atrophy of the heart with its weight of $220 \mathrm{Gm}$. The apex of the heart was formed by both ventricles. The right atrium was dilated as a whole and its wall was $1.4 \mathrm{~mm}$. thick with an endocardial thickening. The foramen ovale was not patent. The tricuspid valve was intact with its circumference of $95 \mathrm{~mm}$. The right ventricle was dilated with its thickness of 2 to $4 \mathrm{~mm}$. A white round-shaped muscular defect was found at the pulmonary conus of the right ventricle, measured $15 \times 12 \mathrm{~mm}$. in size (Fig. 3). On the inner surface, there was a conspicuous decrease of mass of conal muscle, which was shown as markedly concave outflow tract of the right ventricle (Fig. 4). The muscular defect was located at the bottom of this concave outflow tract as shown by an arrow between

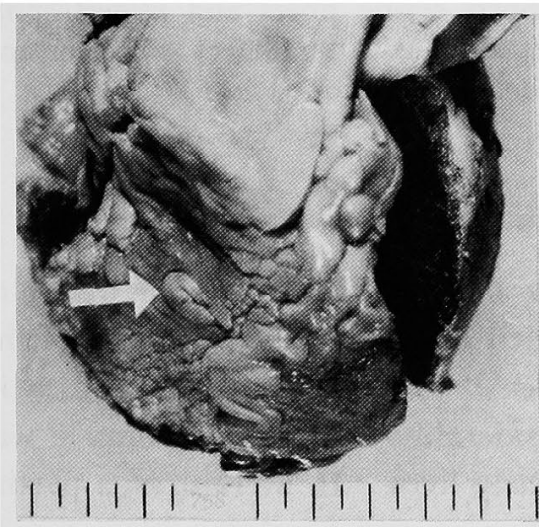

Fig. 3. Anterior view of the heart. Arrow indicates the round muscular defect at the pulmonary conus.

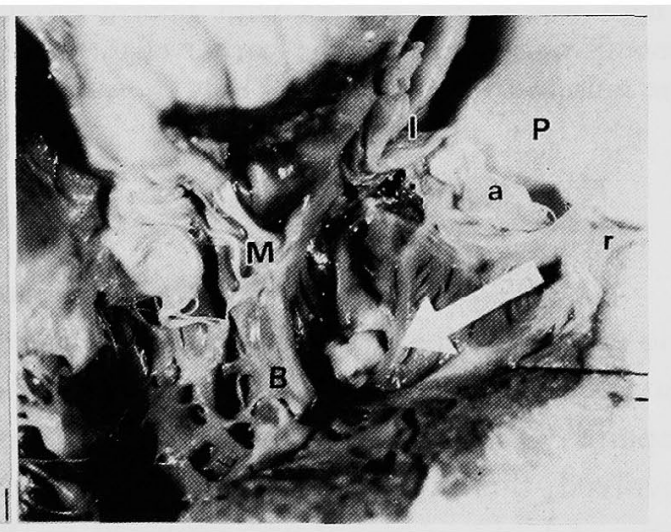

Fig. 4. Inside of the right ventricle. Arrow indicates the muscular defect. P: Pulmonary artery and left(1), right(r) and anterior(a) cusps, M: Muscle of Lancisi, B: Moderator band. 


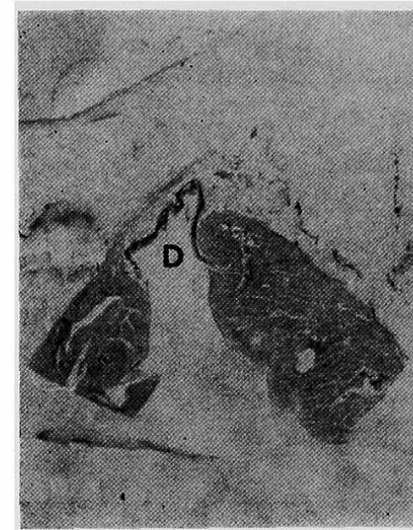

Fig. 5.

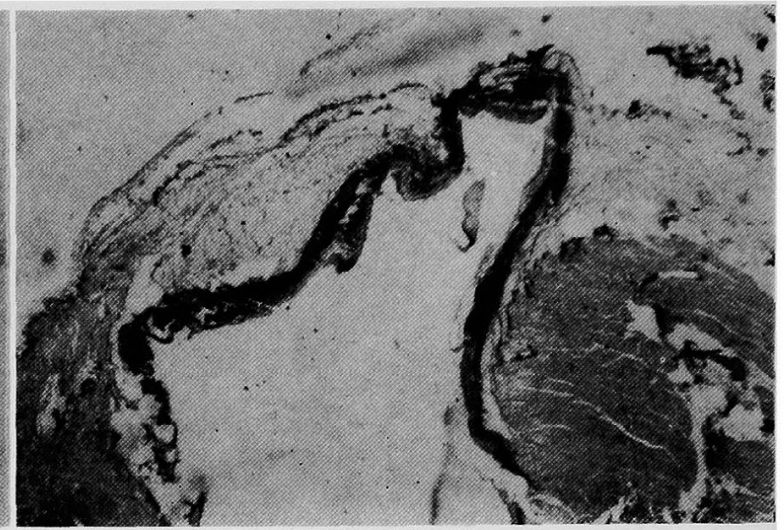

Fig. 6.

Fig. 5. Gross-sectional view of the muscular defect (D) of the right ventricle. Bilateral muscular masses were anterior wall of the right ventricle, and the muscular defect was noted in the center with its markedly thin wall (E.v.G. $\times 1$ ).

Fig. 6. Histological findings of the muscular defect, which consisted of only the epicardial and endocardial layers (E.v.G. $\times 13$ ).

the hypoplastic moderator band and the pulmonic valve. The defect was covered by thick endocardium. The valvular ring was $50 \mathrm{~mm}$. in pulmonary, and $80 \mathrm{~mm}$. in mitral valve. The pulmonary artery and left atrium showed no abnormalities. The left ventricle was not dilated and the wall was $15 \mathrm{~mm}$. thick at the inflow and outflow tracts. The aortic valve was normal with its ring of $70 \mathrm{~mm}$. Coronary ostia were intact and coronary arteries were tortuous with minimal sclerosis including the branch nourishing the pulmonary conus. Extracardiac autopsy findings were bilateral bronchopnenmonia, slight atherosclerosis of the aorta and so on.

Microscopic examination revealed that the portion of the muscular defect consisted of the epicardial and endocardial layers without myocardium (Fig. 5). There was severe fibrosis with poorly developed elastic fibers and hypertrophic smooth muscle cells. The border of the layer adjacent to the defect was clear and the muscle around the defect only showed senile degeneration (Fig. 6).

\section{Comments}

In 1952, Uh1' ${ }^{1)}$ reported the first case of congenital muscular defect of the right ventricle, who died from right-sided heart failure. A review of the autopsy reports showed a total of 13 cases $^{1)-3), 5)-12)}$ including 3 cases in Japan. ${ }^{6), 11)}$ In most of these cases, a considerably large area of muscle was involved, therefore patients died at their early lives. In literatures, a partial form of Uhl's anomaly was reported by Reever) and Gould ${ }^{\text {9) }}$ with a size of $30 \times 70 \mathrm{~mm}$. in the former case and 2 defects of $55 \times 50 \mathrm{~mm}$. and $40 \times 25 \mathrm{~mm}$. in the latter case. They lived to ages of 47 and 66 years, respectively. In our case, the patient survived long enough to 84 years old (oldest case) because 
involved muscle was small $(15 \times 12 \mathrm{~mm}$.) and could have stood the hemodynamic effects during many years.

As for the nature of the muscular defect, no coronary atherosclerosis was found including the branches to the conus, neither focal myocardial damage, degeneration nor fibrosis at the surrounding myocardium except for few degenerations by aging processes. Therefore, this could be concluded as a defect of congenital origin. From the standpoint of architecture of the right ventricular outflow tract, ${ }^{13}$ the partial form of Uhl's disease in this case might be related to the underdevelopment of the conal musculature including the moderator band.

\section{REFERENCES}

1. Uhl, H. S. M.: Bull. Johns Hopkins Hosp. 91 : 197, 1952.

2. Novak, G., Szanto, P. B., Gasul, B., and Dillon, E.: Proc. Inst. Med. Chicago 21: 334, 1957.

3. Taussig, H. B.: Congential Malformation of the Heart, Harvard University Press, Cambridge, p. 138, 1960.

4. Gasul, B. M., Jendrum, B. L., and Arcilla, R. A.: Circulation 22: 752, 1960.

5. Arcilla, R. A. and Gasul, B. M.: J. Pediat. 58: 381, 1961.

6. Hasegawa, T., et al.: Kokyu to Junkan 11:393, 1963.

7. Reeve, R. and MacDonald, D.: Am. J. Cardiol. 14: 415, 1964.

8. Cumming, G. R., Bowman, J. M., and Whytehead, L.: Am. Heart J. 70: 671, 1965.

9. Gould, L., Guttman, A. B., Carrasco, J., and Lyon, A. F.: Am. J. Mcd. 42: 636, 1967.

10. Froment, R., Perrin, A., Loire, R., et Dalloz, Cl.: Arch. Mal. Coeur 61 : 477, 1968.

11. Matsuo, H., et al.: Shinzo 1: 539, 1969.

12. Montella, S., Soresi, V., et Calo, S.: Arch. Mal. Coeur 62: 1183, 1969.

13. Grant, R. P., Downey, F. M., and MacMahon, H.: Circulation 24: 223, 1961. 